OPEN ACCESS

Edited by:

Stefan A. Rensing,

University of Marburg, Germany

Reviewed by:

Pierre-Marc Delaux,

Centre National de la Recherche

Scientifique, France

Sandrine Bonhomme,

French National Institute

for Agricultural Research, France

*Correspondence:

Mark T. Waters

mark.waters@uwa.edu.au

Specialty section:

This article was submitted to Plant Evolution and Development,

a section of the journal

Frontiers in Plant Science

Received: 24 October 2016 Accepted: 15 November 2016 Published: 02 December 2016

Citation:

Sun YK, Flematti GR, Smith SM and Waters MT (2016) Reporter

Gene-Facilitated Detection of Compounds in Arabidopsis Leaf Extracts that Activate the Karrikin Signaling Pathway.

Front. Plant Sci. 7:1799. doi: 10.3389/fpls.2016.01799

\section{Reporter Gene-Facilitated Detection of Compounds in Arabidopsis Leaf Extracts that Activate the Karrikin Signaling Pathway}

\author{
Yueming K. Sun ${ }^{1}$, Gavin R. Flematti ${ }^{2}$, Steven M. Smith ${ }^{3,4}$ and Mark T. Waters ${ }^{1,2 *}$ \\ ${ }^{1}$ Australian Research Council Centre of Excellence in Plant Energy Biology, The University of Western Australia, Perth, WA, \\ Australia, ${ }^{2}$ School of Chemistry and Biochemistry, The University of Western Australia, Perth, WA, Australia, ${ }^{3}$ School of \\ Biological Sciences, University of Tasmania, Hobart, TAS, Australia, ${ }^{4}$ Institute of Genetics and Developmental Biology, \\ Chinese Academy of Sciences, Beijing, China
}

Karrikins are potent germination stimulants generated by the combustion of plant matter. Treatment of Arabidopsis with karrikins triggers a signaling process that is dependent upon a putative receptor protein KARRIKIN INSENSITIVE 2 (KAI2). KAI2 is a homolog of DWARF 14 (D14), the receptor for endogenous strigolactone hormones. Genetic analyses suggest that KAl2 also perceives endogenous signal(s) that are not strigolactones. Activation of KAl2 by addition of karrikins to Arabidopsis plants induces expression of transcripts including D14-LIKE 2 (DLK2). We constructed the synthetic reporter gene DLK2:LUC in Arabidopsis, which comprises the firefly luciferase gene ( $L U C)$ driven by the DLK2 promoter. Here we describe a luminescence-based reporter assay with Arabidopsis seeds to detect chemical signals that can activate the KAl2 signaling pathway. We demonstrate that the DLK2:LUC assay can selectively and sensitively detect karrikins and a functionally similar synthetic strigolactone analog. Crucially we show that crude extracts from Arabidopsis leaves can also activate DLK2:LUC in a KAl2-dependent manner. Our work provides the first direct evidence for the existence of endogenous chemical signals that can activate the KAl2-mediated signaling pathway in Arabidopsis. This sensitive reporter system can now be used for the bioassay-guided purification and identification of putative endogenous KAI2 ligands or their precursors, and endogenous compounds that might modulate the KAl2 signaling pathway.

Keywords: karrikin, plant hormone, reporters, chemical biology, strigolactone, Arabidopsis, germination

\section{INTRODUCTION}

Karrikins (KAR) are potent compounds in wildfire smoke that stimulate germination of many plant species (Flematti et al., 2004), including Arabidopsis thaliana (Nelson et al., 2009). In Arabidopsis, response to KAR requires the F-box protein MORE AXILLARY GROWTH 2 (MAX2; Nelson et al., 2011) and the $\alpha / \beta$-fold hydrolase KARRIKIN INSENSITIVE 2 (KAI2; Waters et al., 2012). Surprisingly, kai2 and max2 mutants are not only insensitive to KAR, but also show delayed germination and abnormal seedling growth phenotypes. Meanwhile, loss-of-function 
mutations in SUPPRESSOR OF MAX2 1 (SMAX1) and its paralog SMAX1-LIKE2 (SMXL2) induce constitutive KAR responses (Stanga et al., 2013, 2016). These mutant phenotypes suggest that the karrikin signaling pathway defined by KAI2, MAX2, and SMAX1/SMXL2 has endogenous functions in plant development that extend beyond mediating responses to KAR.

Karrikins are butenolide compounds structurally related to strigolactones (SLs), an endogenous set of butenolides that regulate shoot branching and other developmental processes (Waldie et al., 2014). Response to SL also requires MAX2 and a paralog of KAI2, namely DWARF14 (D14; Arite et al., 2009). Degradation of the SMAX1-LIKE proteins is induced by SL (Jiang et al., 2013; Zhou et al., 2013; Soundappan et al., 2015; Wang et al., 2015). As hydrolases, both KAI2 and D14 possess a catalytic triad (Ser, His, Asp) that is required for the function of both proteins (Hamiaux et al., 2012; Waters et al., 2015b). Three studies have demonstrated that D14 is activated by covalent modification of the catalytic triad following SL hydrolysis (Zhao et al., 2013; de Saint Germain et al., 2016; Yao et al., 2016), confirming D14 as a SL receptor (Hamiaux et al., 2012). Several reports have also demonstrated interaction of KAR with Arabidopsis KAI2 and its homologs (Guo et al., 2013; Kagiyama et al., 2013; Xu et al., 2016), but no covalent interaction has been reported. Additional butenolides such as synthetic SL isomer GR24 $4^{\text {ent }}-5 \mathrm{DS}$ also activate KAI2 signaling, while mutation of the catalytic triad abolishes hydrolysis and signaling (Scaffidi et al., 2014; Waters et al., 2015b). As such, it is likely that KAI2 and D14 have similar modes of action as butenolide receptors. To date, no biosynthetic source of karrikins or karrikin-like compounds has been discovered. Instead, given the extensive similarities between KAI2 and D14 signaling and the fact that the SL biosynthetic pathway is not required for KAI2 signaling (Scaffidi et al., 2013), we have hypothesized that KAI2 may perceive an unknown endogenous KAI2 ligand (KL; Flematti et al., 2013). Recent genetic studies on KAI2 orthologs from parasitic plant species have provided indirect evidence to support this KL hypothesis (Conn et al., 2015; Conn and Nelson, 2016). Here we examine the KL hypothesis directly by asking whether the signaling pathway defined by KAI2-MAX2-SMAX1 can be activated by metabolites in plant extracts.

At the physiological level, KAR stimulates seed germination and inhibits hypocotyl elongation. However, other growth substances besides KL in plant extracts could potentially affect germination and seedling development in the same or opposite way as KL. Therefore, physiological responses to treatment with plant extracts could reflect a confounding and combinatorial effect of several active compounds, rather than any single class of compound.

Accordingly, we sought molecular responses to $\mathrm{KL}$ that are specifically dependent on the KAI2-MAX2-SMAX1 pathway. Among KAR-responsive transcripts, D14-LIKE 2 (DLK2) transcription is strongly induced in a MAX2- and KAI2- or D14-dependent manner upon KAR or SL treatment (Waters et al., 2012; Scaffidi et al., 2014). Since D14 is comparatively weakly expressed in Arabidopsis seeds, DLK2 serves as an explicit marker for KAI2-dependent signaling in seeds. Compared to wild type, DLK2 transcripts are significantly less abundant in kai2 and max2 mutants (Waters et al., 2012), and more abundant in smax1 and smxl2 mutants (Stanga et al., 2013, 2016). These observations led us to investigate whether DLK2 could serve as a specific indicator for activation of the KAI2-MAX2-SMAX1 pathway.

First we developed a rapid luminescence-based assay for upregulation of DLK2 in Arabidopsis seeds. We then established that the assay is sensitive and specific to KAR treatment compared to other known plant growth substances. Lastly we used the assay to examine Arabidopsis leaf extracts for KL activity.

\section{MATERIALS AND METHODS}

\section{Chemicals}

Karrikins $\left(\mathrm{KAR}_{1}, \mathrm{KAR}_{2}\right), \mathrm{GR} 24^{5 \mathrm{DS}}$, and GR24 $4^{\text {ent-5DS}}$ were prepared as described (Flematti et al., 2007; Goddard-Borger et al., 2007; Scaffidi et al., 2014) and dissolved as $10 \mathrm{mM}$ stock solutions in acetone. Epibrassinolide (Sigma E1641), gibberellic acid (GA 4 from L. N. Mander, Australian National University), 3indoleacetic acid (Sigma I2886), (+)-cis, trans-abscisic acid (AG Scientific A-1103) and ( \pm )-jasmonic acid (Sigma J2500) were dissolved in acetone as $5,10,10,10$, and $50 \mathrm{mM}$ stock solutions, respectively.

\section{DLK2:LUC Reporter Line Construction}

The DLK2 promoter sequence was defined as the $3566 \mathrm{bp}$ of genomic sequence spanning the annotated transcriptional start site of DLK2 (At3g24420) and 103 bp downstream of the annotated $3^{\prime}$ UTR of the preceding gene (At3g24430). We also included the DLK2 $5^{\prime} \mathrm{UTR}$ (31 bp). This sequence was amplified by PCR using Phusion polymerase (New England Biolabs). Oligonucleotides were (5'-AAAAAAGCAGGCTCAA ACGCGATAACCTTTTCA-3') and MW446 (5'-CAAGAAAG CTGGGTGCTTAAGTACAAGAGTTTTG-3'); regions of homology to Arabidopsis genomic DNA are underlined. Gatewaycompatible attB recombination sites were added in a further round of PCR and the resulting product cloned into pDONR207. This intermediate plasmid was recombined with the binary vector pHGWL7 (Karimi et al., 2002), inserting the DLK2 promoter sequence upstream of firefly luciferase coding sequence.

The DLK2:LUC construct was introduced into Arabidopsis Ler background by floral dipping. Primary transformants were selected on $20 \mu \mathrm{g} \mathrm{ml}^{-1}$ hygromycin B. Six lines that segregated 3:1 for hygromycin resistance were propagated to homozygosity and subsequently screened for LUC activity in response to KAR and racemic GR24. The most robustly responding line was then crossed with kai2-2 (Ler) (Waters et al., 2012) and experiments were performed on the $\mathrm{F}_{3}$ generation homozygous for both kai2-2 and the DLK2:LUC transgene.

\section{Quantitative PCR}

Twenty milligrams of Arabidopsis seeds were imbibed in $1 \mathrm{ml}$ water supplemented with KAR or acetone for $48 \mathrm{~h}$ at $20^{\circ} \mathrm{C}$ under continuous light. RNA extraction and quantitative PCR was conducted as described (Waters et al., 2012). Oligonucleotides for 
LUC transcripts were $5^{\prime}$-ATTCTTTATGCCGGTGTTGG-3' and 5'-TGTTGAGCAATTCACGTTCA-3'.

\section{Firefly Luciferase Standard Curve}

Recombinant firefly luciferase in buffered aqueous solution

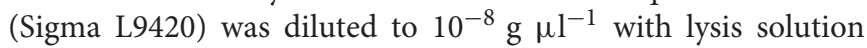
(25 mM Tris-phosphate $\mathrm{pH} 7.8,2 \mathrm{mM}$ DTT, $2 \mathrm{mM} \mathrm{1,2-}$ diaminocyclohexane-tetraacetic acid (DACTAA), 10\% glycerol, $1 \%$ Triton X-100). A 10-fold dilution series in lysis solution was

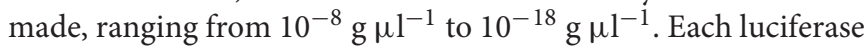
stock solution was further diluted 1 in 20 with lysis solution and $20 \mu \mathrm{l}$ of each dilution was transferred to a white opaque 96-well assay plate (Sigma-Aldrich, CLS3912) in triplicate. Triplicate lysis solution served as background control.

A POLARstar OPTIMA (BMG LABTECH) was used to measure luminescence. The injector was rinsed with $4.5 \mathrm{ml}$ water, then primed with $1 \mathrm{ml}$ Luciferase Assay Reagent (LAR; $15 \mathrm{mM} \mathrm{K}_{2} \mathrm{PO}_{4} / \mathrm{KH}_{2} \mathrm{PO}_{4} \mathrm{pH}$ 7.8, $25 \mathrm{mM}$ Gly-Gly, 4 mM EGTA, $15 \mathrm{mM} \mathrm{MgSO}_{4}, 2 \mathrm{mM}$ ATP, $1 \mathrm{mM}$ DTT, $0.1 \mathrm{mM}$ Coenzyme A, $120 \mu \mathrm{M}$ luciferin) (Dyer et al., 2000). The instrument was programmed to inject $100 \mu \mathrm{l} \mathrm{LAR}(260 \mu \mathrm{l} /$ second) one well at a time, to shake the assay plate for $5 \mathrm{~s}$ after each injection ( $1 \mathrm{~mm}$ shaking width, $600 \mathrm{rpm}$ ), and to measure luminescence signal for $5 \mathrm{~s}$ using the top optic (gain 4095). The assay plate was read from the lowest to the highest luciferase concentration, to avoid light contamination caused by higher-concentration luciferase samples. After measurements were completed, the mean luminescence signals produced by the background control lysis solution was subtracted from each luminescence reading produced by luciferase samples, to obtain the net reading for each sample.

\section{Assaying DLK2:LUC Activity}

Dry Arabidopsis seeds (Landsberg erecta; $2.5 \mathrm{mg}$ ) were distributed with a home-made seed scoop into $1.2 \mathrm{ml}$ tubes in eight-tube strips (Astral Scientific, I1720-00) held by a rack. The seeds were collected at the bottom by brief centrifugation. Compound stocks (1000-fold) in acetone were diluted in water and added to each tube $(100 \mu \mathrm{l})$. The seeds were resuspended in treatment solutions by flicking the tubes. The seed tubes were incubated at $20^{\circ} \mathrm{C}$ under continuous light for between 24 and $72 \mathrm{~h}$.

After incubation, the seed tubes were centrifuged at $4000 \mathrm{rpm}$ for $5 \mathrm{~min}$ to collect seeds at the bottom. Treatment solution was removed from each tube using a multi-channel pipette set at $75 \mu \mathrm{l}$, with care taken not to remove any seeds. Two, $1 \mathrm{~mm}$ diameter stainless steel balls, were distributed into each tube. Lysis solution $(80 \mu \mathrm{l})$ was added to each tube. The seed tissues were ground in lysis solution using a mixer mill at 30/s for $1 \mathrm{~min}$ twice. The seed extracts were centrifuged at $4000 \mathrm{rpm}$ for 10 min to pellet tissue debris. The supernatant $(20 \mu \mathrm{l})$, containing extracted luciferase enzyme, was transferred to a white opaque 96-well assay plate (Sigma-Aldrich, CLS3912). Triplicate lysis solution served as background control.

Luminescence was measured as described in the previous section. The plate reading direction was perpendicular to the biological replicates loading direction, to avoid time-dependent bias.
The net readings were obtained as described in the previous section. The mean net luminescence reading was taken for mock and each treatment. Fold change in LUC activity was calculated by the following formula:

$$
\begin{aligned}
& \text { Fold change in LUC activity }= \\
& \qquad \frac{\text { mean net luminescence reading [treatment] }}{\text { mean net luminescence reading [mock] }}
\end{aligned}
$$

Standard errors of mean net luminescence readings were calculated and scaled to the fold change in LUC activity.

\section{Growth of Arabidopsis and Extraction of Metabolites}

Arabidopsis Ler seeds $(0.6 \mathrm{ml})$ were sown directly on soil (peat:vermiculite:perlite 6:1:1) in 20 rectangular pots (Garden City Plastics, PUNSTX, volume $400 \mathrm{ml}$ ) distributed across two trays. The seeds were stratified for 3 days in the dark at $4^{\circ} \mathrm{C}$, before being transferred to a climate-controlled growth room $(8 \mathrm{~h}$ light $/ 16 \mathrm{~h}$ dark photoperiod, $22^{\circ} \mathrm{C}$ light $/ 16^{\circ} \mathrm{C}$ dark temperature cycle, $100-150 \mu \mathrm{mol} \mathrm{m}^{-2} \mathrm{~s}^{-1} \mathrm{PAR}, 60 \%$ relative humidity). Rosette tissue from 7-week old plants prior to flowering was harvested, weighed (circa $200 \mathrm{~g} \mathrm{FW}$ ), and frozen in liquid nitrogen. Leaf tissue was ground in liquid nitrogen with a mortar and pestle, and extracted with $80 \%(\mathrm{v} / \mathrm{v})$ methanol in water at $4{ }^{\circ} \mathrm{C}$ overnight $(10 \mathrm{ml}$ per gram $\mathrm{FW})$. The next day, the methanol/water extract was filtered with Whatman filter paper $(18.5 \mathrm{~cm}$, No. 4) to remove tissue debris. Methanol was removed under reduced pressure at $40^{\circ} \mathrm{C}$. The remaining aqueous extract was diluted with water to $100 \mathrm{ml}$, and extracted with ethyl acetate $(3 \times 100 \mathrm{ml})$. The aqueous layer was concentrated under reduced pressure at $40^{\circ} \mathrm{C}$ to $10 \mathrm{ml}$ and stored at $-20^{\circ} \mathrm{C}$. The combined ethyl acetate extract was evaporated to dryness under reduced pressure to give $0.8 \mathrm{~g}$ solid material. The ethyl acetate extract was re-constituted with $10 \mathrm{ml}$ of purified water on a rotating wheel overnight at $4^{\circ} \mathrm{C}$. A total of $0.1 \%$ of each extract (annotated as "stock"), and dilutions of $1 / 5$ and $1 / 25$ were tested with the $D L K 2: L U C$ assay.

\section{Statistical Analysis}

Significance groupings were determined using one-way ANOVAs based on Honestly Significant Differences (HSD) Test. The analyses were performed in R Program v3.2.3, using the package "agricolae."

\section{RESULTS}

\section{Development of the DLK2:LUC Reporter Assay}

To measure DLK2 expression while avoiding laborious RNA extraction and quantitative PCR steps, we fused the DLK2 promoter (defined as $3566 \mathrm{bp}$ upstream of the transcriptional start site, plus $31 \mathrm{bp}$ of $5^{\prime} \mathrm{UTR}$ ) to the firefly luciferase (LUC) gene to make the reporter DLK2:LUC (Figure 1A). We chose such a long intergenic region to avoid excluding potential 
A
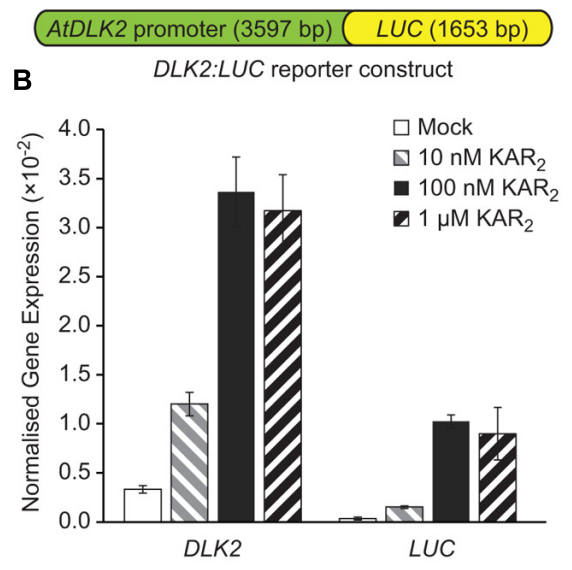

C

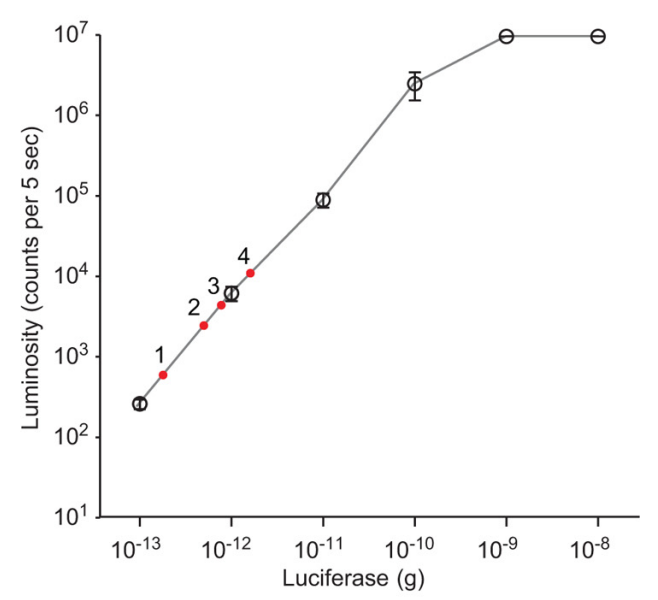

D

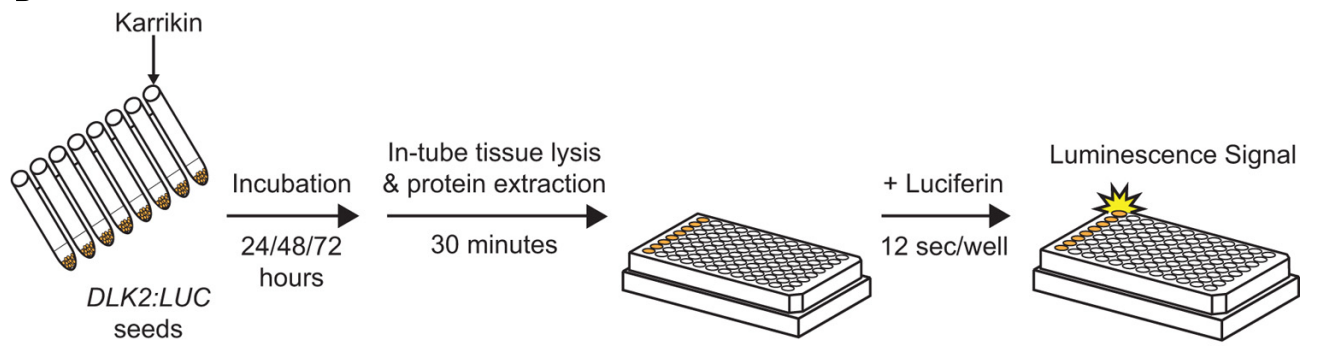

FIGURE 1 | Development of the DLK2:LUC reporter assay. (A) Schematic representation of the DLK2:LUC reporter construct that was transformed to Arabidopsis wild-type Ler (DLK2:LUC [Ler]) and crossed into the karrikin insensitive 2-2 (kai2-2) mutant background (DLK2:LUC [kai2]). The construct contains $3566 \mathrm{bp}$ of intergenic sequence upstream of the transcriptional start site of D14-LIKE 2 (DLK2, At3g24420), 31 bp of DLK2 5'UTR, and 1653 bp of FIREFLY LUCIFERASE (LUC) coding sequence. (B) Response of DLK2 and LUC transcripts to karrikin treatments in DLK2:LUC reporter seeds. Transcript abundance was normalized to CACS (At5g46630). Error bars show standard errors (SE) with $n=3$ batches of seeds. In this assay, neither DLK2 nor LUC transcripts could be detected reliably in the DLK2:LUC [kai2] reporter seeds. (C) Standard curve of firefly luciferase enzymatic activity using purified firefly luciferase enzyme and D-luciferin substrate. Error bars show SE with $n=3$ experimental replicates, where each dilution was measured with three technical replicates. The red dots represent a typical dataset where luciferase activity in DLK2:LUC [Ler] is induced by (1) mock; (2) $10 \mathrm{nM} \mathrm{KAR}_{2}$; (3) $100 \mathrm{nM} \mathrm{KAR} 2$; (4) $1 \mu \mathrm{MM} \mathrm{KAR} 2$ over $72 \mathrm{~h}$. (D) Illustration of the DLK2:LUC assay procedure (illustration of the 96-well plate is adapted from Promega's Technical Bulletin - Luciferase Assay System 12/11).

upstream regulatory elements. We reasoned that, in a wild type background, KAR would activate LUC gene expression and induce luciferase activity, but that this response would be absent in kai2 mutants. Accordingly we generated transgenic Arabidopsis expressing the reporter construct in Ler ecotype, and then crossed a suitably responding transgenic line with kai2-2. We first tested induction of $L U C$ gene expression upon KAR treatments using quantitative RT-PCR, in comparison with the endogenous DLK2 gene in Arabidopsis seeds. In imbibed seed, $D L K 2$ transcripts increase in response to KAR via KAI2, while signaling via D14 is low or absent (Waters et al., 2012). We found that both DLK2 and LUC transcripts were induced by $\mathrm{KAR}_{2}$ treatments (Figure 1B). While levels of $L U C$ transcripts were lower than DLK2 transcripts (relative to CACS reference transcripts), the patterns of induction in response to $\mathrm{KAR}_{2}$ were very similar.

We then adopted a luciferase assay system in a 96-well plate format to increase throughput. We generated an enzymatic activity standard curve for the assay system using recombinant firefly luciferase standards (Figure 1C). In our hands, the system detection limit is $10^{-13} \mathrm{~g}$ of luciferase, with a linear response between $10^{-13} \mathrm{~g}$ to $10^{-9} \mathrm{~g}$ of luciferase enzyme, which compares favorably with published data (Dyer et al., 2000).

We used a cell-free luciferase detection method to avoid blocking of luminescence signals by seed tissues (Figure 1D). Compounds for treatment were dissolved in water and applied to the DLK2:LUC reporter seeds. After imbibition, cell lysate was prepared from the seeds, and luminescence was measured by an automated plate reader. The luminescence signal produced by a particular treatment was expressed relative to the signal produced by seeds treated with water alone (mock treatment).

\section{Validation of the DLK2:LUC Reporter Assay}

To demonstrate the sensitivity of the DLK2:LUC assay, we applied a concentration gradient of the two karrikins $\mathrm{KAR}_{1}$ and $\mathrm{KAR}_{2}$ over a time-course of $72 \mathrm{~h}$ to the DLK2:LUC 
A

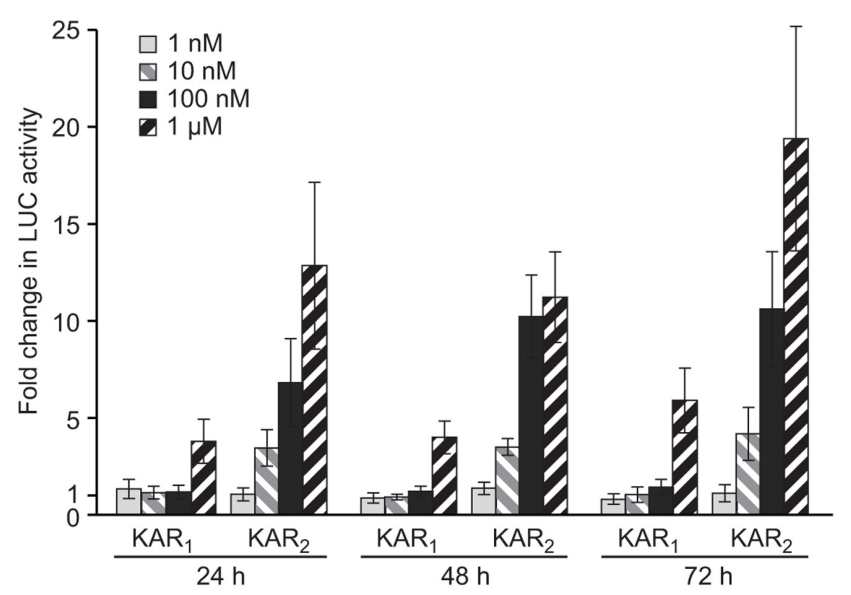

B

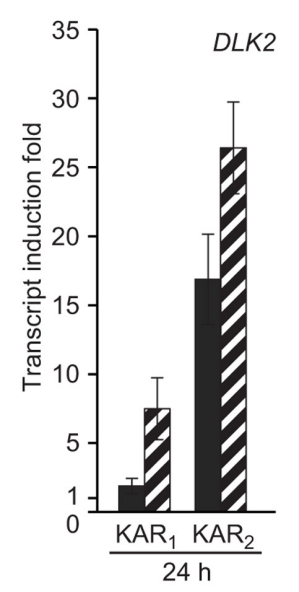

C

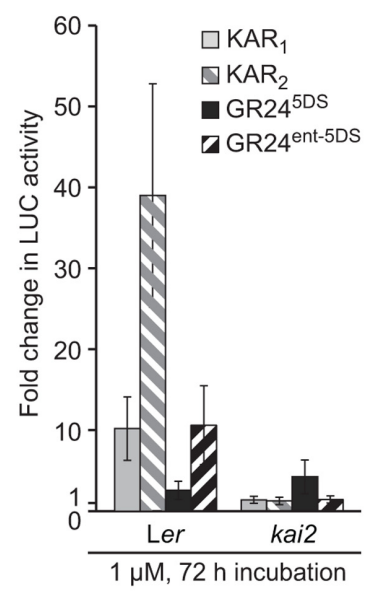

D

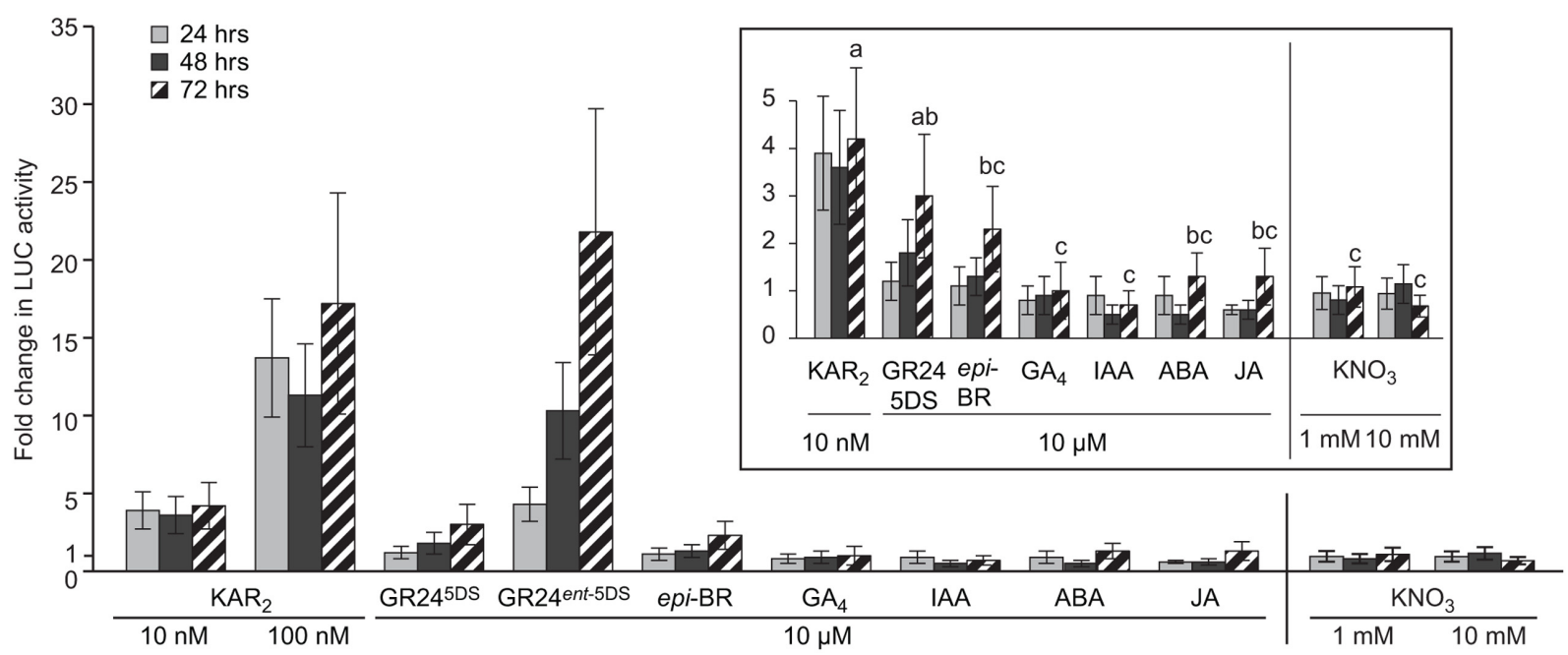

FIGURE 2 | DLK2:LUC Specifically Responds to KAI2 Substrates. (A) Sensitivity of the DLK2:LUC assay to KAR ${ }_{1}$ and $K A R_{2}$ at a range of concentrations over 24, 48, and $72 \mathrm{~h}$. Data are expressed as fold change in LUC activity relative to a mock sample of seeds treated with water for the same duration. (B) Sensitivity of $D L K 2$ transcripts to $K A R_{1}$ and $K A R_{2}$ at a range of concentrations over $24 \mathrm{~h}$ in Ler seeds. Data are expressed as fold change relative to mock sample of seeds treated with water for the same duration. (C) Specificity of the DLK2:LUC assay toward karrikins and strigolactones in Ler and kai2 backgrounds treated for $72 \mathrm{~h}$. (D) Specificity of the DLK2:LUC assay toward strigolactone analogs, selected plant hormones, and the germination stimulant $\mathrm{KNO}_{3}$. Vertical line indicates separate experiments. Inset shows the same data scaled for smaller fold changes. Shared lower case letters indicate no significant difference between $72 \mathrm{~h}$ treatments, and "C" indicates no significant difference from mock treatment (ANOVA; $P<0.05$ ). In all charts, error bars depict SE, $n=8$ replicates.

[Ler] reporter seeds. Using this method, KAR response can be detected after $24 \mathrm{~h}$ (Figure 2A). The system is substantially more sensitive to $\mathrm{KAR}_{2}$ treatment since $10 \mathrm{nM} \mathrm{KAR}$ induced a fourfold change in activity within $24 \mathrm{~h}$, while $1 \mu \mathrm{M} \mathrm{KAR}_{1}$ was necessary for a similar response. This preference for $\mathrm{KAR}_{2}$ is consistent with multiple responses in Arabidopsis (Nelson et al., 2011; Waters et al., 2012, 2015a), as well as for endogenous DLK2 transcripts themselves (Figure 2B). To demonstrate the specificity of the DLK2:LUC assay system in differentiating responses to KAR and $\mathrm{SL}$, we applied $\mathrm{KAR}_{1}$, $\mathrm{KAR}_{2}$, and two enantiomers of the synthetic SL analog GR24 to DLK2:LUC [Ler] and DLK2:LUC [kai2] seeds for $72 \mathrm{~h}$.
GR24 ${ }^{5 D S}$ is a synthetic SL with stereochemistry consistent with natural SLs that act preferentially through D14, whereas its nonnaturally configured enantiomer GR24 ${ }^{\text {ent }-5 D S}$ operates largely via KAI2 (Scaffidi et al., 2014; Waters et al., 2015a). As expected, $D L K 2: L U C$ [Ler] seeds responded strongly to $\mathrm{KAR}_{1}, \mathrm{KAR}_{2}$ and GR2 $4^{\text {ent }}-5 \mathrm{DS}$, but only marginally to GR24 ${ }^{5 \mathrm{DS}}$ (Figure 2C). Importantly, the responses to $\mathrm{KAR}_{1}, \mathrm{KAR}_{2}$, and GR24 $4^{\text {ent }}$-5DS were eliminated in the DLK2:LUC [kai2] seeds. These data demonstrate that induction of LUC activity is ligand-specific and KAI2-dependent.

To investigate further the specificity of the DLK2:LUC assay system, we applied a variety of plant hormones 
A

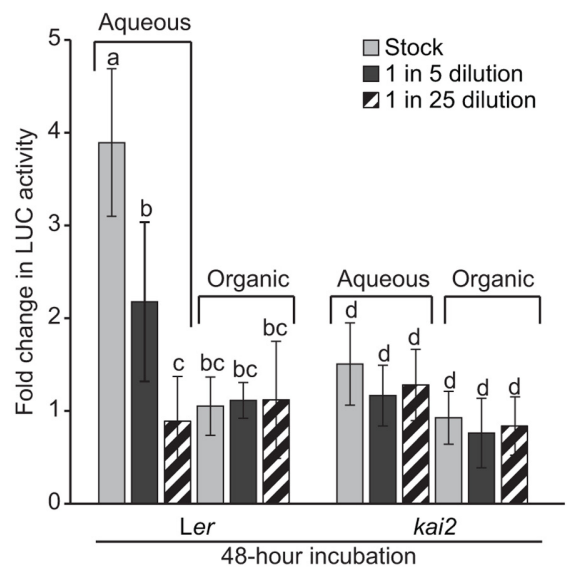

B

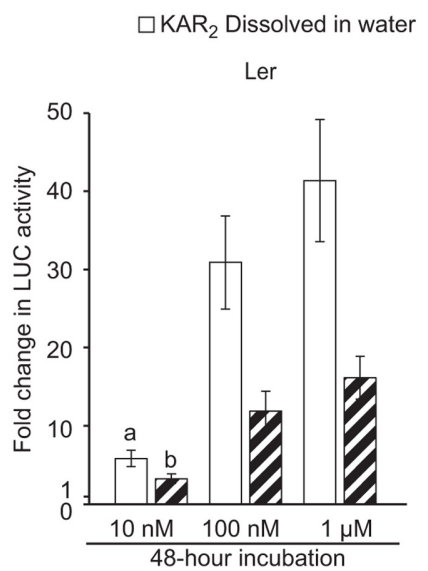

$\mathrm{KAR}_{2}$ Dissolved in organic extract kai2

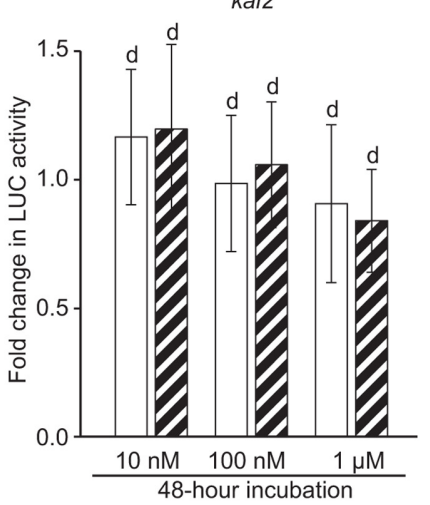

FIGURE 3 | DLK2:LUC activity is induced by Arabidopsis leaf extracts. (A) Activity of Arabidopsis leaf extracts in inducing DLK2:LUC expression in a KAl2-dependent manner. Extracts were separated into aqueous and organic fractions and applied separately. Stock treatment is equivalent to $0.2 \mathrm{~g}$ of rosette tissue from 7-week old Arabidopsis plants grown under an $8 \mathrm{~h}$ day $/ 16 \mathrm{~h}$ night photoperiod. Error bars depict SE, $n=3$ replicates. (B) Activity of KAR 2 standard dissolved either in water or in the organic fraction of the Arabidopsis leaf extract. The concentration of organic extract is equivalent to the stock treatment concentration in (A). Error bars depict SE, $n=8$ replicates. Shared lower case letters indicate no significant difference between treatments within the same genotype. "c" and "d" indicate no significant difference from mock-treated DLK2:LUC [Ler] and DLK2:LUC [kai2] seeds, respectively. (ANOVA; $P<0.05$ ).

[epibrassinosteroid (epi-BR); gibberellic acid ( $\left.\mathrm{GA}_{4}\right)$; auxin (IAA); abscisic acid (ABA); jasmonic acid (JA)] and the germination stimulant $\mathrm{KNO}_{3}$ over a period of $72 \mathrm{~h}$. We also included the two enantiomers of GR24. We found that while $100 \mathrm{nM} \mathrm{KAR}_{2}$ and $10 \mu \mathrm{M}$ GR2 $4^{\text {ent-5DS }}$ induced a 10-fold increase in luciferase activity after $48 \mathrm{~h}$, the other tested compounds were essentially inactive (Figure 2D). Therefore DLK2:LUC activity is not affected by these known plant hormones or $\mathrm{KNO}_{3}$. There was a limited response to GR24 ${ }^{5 \mathrm{DS}}$ after $72 \mathrm{~h}$, which may indicate increasing expression of the SL receptor D14 after prolonged seed imbibition.

\section{Detection of DLK2:LUC Induction Activity in Arabidopsis Metabolites Extracts}

Having validated the sensitivity and specificity of the DLK2:LUC assay, we used it to test whether compounds extracted from Arabidopsis tissue could activate the KAI2-MAX2-SMAX1 signaling pathway. We reasoned that leaf material would be a good source of KL because this was a simple way to gather relatively large amounts of tissue. In addition, the defective leaf development phenotype of kai2 mutants indicated that KAI2dependent signaling is active beyond the seed and seedling stages where large amounts of material would be more difficult to obtain.

We extracted metabolites from Arabidopsis rosettes with $80 \%(\mathrm{v} / \mathrm{v})$ methanol in water. After removing the methanol by evaporation, we added ethyl acetate and partitioned the crude extract into two layers: aqueous (water) and organic (ethyl acetate). The partitioning method was originally optimized to extract $\mathrm{KAR}_{1}$ from aqueous solutions. We applied a dilution series of each extract to the DLK2:LUC [Ler] and DLK2:LUC [kai2] reporter seeds. We found that unknown metabolites in the aqueous layer increased DLK2 expression fourfold within
$48 \mathrm{~h}$ in a KAI2-dependent manner, whereas metabolites in the organic layer were inactive in this assay (Figure 3A). As such, we infer that compounds present in the Arabidopsis leaf extract can activate the KAI2-MAX2-SMAX1 signaling pathway. To our surprise, the active compound(s) appeared to be water-soluble and inefficiently extracted into ethyl acetate. This is in marked contrast to $\mathrm{KAR}_{1}$ and SLs, which are usually extracted into organic solvents such as ether or ethyl acetate (Yasuda et al., 2003; Flematti et al., 2004).

We considered that the organic layer might in fact be active, but also might contain inhibitors that prevent the activation of DLK2:LUC. To detect such inhibitors, we compared the relative activity of $\mathrm{KAR}_{2}$ dissolved in water versus that of $\mathrm{KAR}_{2}$ dissolved in the organic layer (Figure 3B). We found that $\mathrm{KAR}_{2}$ dissolved in the organic layer induced DLK2:LUC to approximately half the level of $\mathrm{KAR}_{2}$ dissolved in water, suggesting that inhibitors were likely present but were insufficient to completely suppress DLK2:LUC activation, even at low $\mathrm{KAR}_{2}$ concentration. Because we only observed activity in the aqueous fraction (Figure $\mathbf{3 A}$ ), it is unlikely that there was appreciable activity in the organic layer that was suppressed by inhibitors. We cannot prove conclusively the absence of any activity in the organic layer because any extraction or recovery process might exclude some compounds. However, on the basis of these results, we conclude that the active compound(s) is primarily water-soluble.

\section{DISCUSSION}

The classical plant hormones were discovered through their bioactivities when applied exogenously. For example, the observation that extracts of senescent leaf tissues accelerated 
abscission of de-bladed young leaves led to the hypothesis of a new hormone (Osborne, 1955), which was later identified as abscisic acid (Liu and Carnsdagger, 1961). In this case, a clearly defined source of bioactivity (senescent leaves) contained the hypothetical hormone, while a biological response (abscission) indicated the effect of the hormone. In contrast, the hypothesis of a KAI2 ligand (KL) is distinct in nature, because rather than starting from an observed bioactivity, the existence of a hormone is inferred from genetic analyses and by analogy to SL signaling. Therefore, to isolate $\mathrm{KL}$, it is necessary first to identify a source of bioactivity, and then determine a specific biological response that indicates the presence of $\mathrm{KL}$ bioactivity in the source. Here, we identified Arabidopsis leaf extracts as a source for KL bioactivity, and DLK2 induction as the specific biological response. The resulting reporter system allows the source-response relationship to be assayed readily. The approach adopted here mirrors that of Adhikari et al. (2013), who used a reporter system to establish both the presence and chemical nature of the 'bypass' signal that controls shoot growth, although its identity is yet to be determined.

The main evidence for KAI2 being the receptor for an unknown endogenous compound is fivefold. First, a KAI2-like protein is the evolutionary ancestor of D14, the strigolactone receptor (Delaux et al., 2012; Waters et al., 2012, 2015b). Second, KAI2-dependent signaling requires the catalytic triad as does D14, and this requirement is evolutionarily conserved between lycophytes and angiosperms (Waters et al., 2015a,b). Third, some divergent KAI2 homologs in parasitic weeds within the Orobanchaceae have become specialized for strigolactone perception, while more evolutionarily conserved homologs have retained a strigolactone-independent function similar to that of AtKAI2 (Conn et al., 2015; Toh et al., 2015; Conn and Nelson, 2016). Fourth, both KAI2- and D14dependent signaling operates via the same family of SMXL repressor proteins (Jiang et al., 2013; Stanga et al., 2013, 2016; Zhou et al., 2013; Soundappan et al., 2015; Wang et al., 2015). Finally, kai2 and max2 mutants of Arabidopsis both share seed germination and seedling morphogenesis phenotypes that are opposite to the effects of karrikin treatment and that are not found in strigolactone mutants (Nelson et al., 2011; Waters et al., 2012). In agreement with these compelling molecular-genetic evidence, here we have demonstrated that compounds extracted from plant tissue can activate KAI2-dependent signaling, further supporting the existence of KL.

The DLK2:LUC assay we describe here can be scaled up and adapted to isolate the active compound(s), and potentially identify KL. There are at least three major challenges to doing so. First, the response of DLK2:LUC to leaf extracts is comparable to just $10 \mathrm{nM} \mathrm{KAR}$, and $\mathrm{KL}$ is presumably a more efficient KAI2 ligand than $\mathrm{KAR}_{2}$. This observation suggests that the active compound(s) is presumably very low in abundance, necessitating large-scale growth of source material. The structural elucidation of the gibberellin $\mathrm{GA}_{32}$, for example, involved the isolation of $38 \mathrm{mg}$ from $35 \mathrm{~kg}$ of peach seeds, themselves isolated from one ton of fruit (Yamaguchi et al.,
1970; Mander, 2003). As a further example, the isolation of ABA from cotton leaf petioles required $10 \mathrm{~kg}$ of dry plant material to isolate just $1 \mathrm{mg}$ (Liu and Carnsdagger, 1961). Such low yields probably preclude the use of Arabidopsis leaves as a source, necessitating a hunt for a richer or commercially available source. The second challenge may involve the isolation of potentially unstable compounds (e.g., if $\mathrm{KL}$ is similar to strigolactones, which hydrolyse in water) through several rounds of separation. Investigation of different solvents, extraction techniques and separation methods will assist in solving this problem. Finally, the reporter assay itself could be refined to improve specificity and sensitivity. For example, use of a $d 14$ mutant background could exclude false positives from strigolactones, which may activate the system at later stages of seed germination (Figure 2D). Conceivably, sensitivity improvements could result from an optimized, synthetic promoter consisting of concatemerized "KAR-response" elements identified from the DLK2 promoter.

Based on the broad similarities between karrikins, SLs and their respective receptors, we would expect $\mathrm{KL}$ to be a hydrophobic butenolide compound or group of compounds. However, it should be noted that the active compound(s) detected by this technique might not be the direct ligand(s) of KAI2. Although the assay indicates KAI2-specific induction of DLK2 expression, it does not differentiate $\mathrm{KL}$ from other signals upstream of KAI2. Potentially, the activity observed in this assay - which was unexpectedly water-soluble - might originate from a biosynthetic precursor of $\mathrm{KL}$, or a stimulator of KL biosynthesis. Nevertheless, identifying any such chemical interactors of the KAI2-MAX2-SMAX1 pathway would greatly enhance our understanding of the endogenous functions of the pathway. Discovering the identity of $\mathrm{KL}$ would be a major advance for plant hormone biology. Furthermore, KL could be beneficial as an agrichemical in applications where KAI2-mediated control of seed germination and early seedling establishment is critical.

\section{AUTHOR CONTRIBUTIONS}

YS, GF, SS, and MW designed the research. YS and MW performed the research. YS, GF, SS, and MW analyzed the data and wrote the manuscript.

\section{FUNDING}

This work was supported by grants from the Australian Research Council to SS and GF (DP130103646) and to MW (FT150100162). YS is the recipient of an International Postgraduate Research Scholarship from the Australian Government.

\section{ACKNOWLEDGMENT}

We thank Adrian Scaffidi for synthesizing the karrikin and strigolactone standards. We are also grateful to David Nelson and Nithya Palanivelu for valuable discussions. 


\section{REFERENCES}

Adhikari, E., Lee, D.-K., Giavalisco, P., and Sieburth, L. E. (2013). Long-distance signaling in bypass 1 mutants: bioassay development reveals the bps signal to be a metabolite. Mol. Plant 6, 164-173. doi: 10.1093/mp/sss129

Arite, T., Umehara, M., Ishikawa, S., Hanada, A., Maekawa, M., Yamaguchi, S., et al. (2009). D14, a strigolactone-insensitive mutant of rice, shows an accelerated outgrowth of tillers. Plant Cell Physiol. 50, 1416-1424. doi: 10.1093/pcp/ pcp091

Conn, C. E., Bythell-Douglas, R., Neumann, D., Yoshida, S., Whittington, B., Westwood, J. H., et al. (2015). Convergent evolution of strigolactone perception enabled host detection in parasitic plants. Science 349, 540-543. doi: 10.1126/ science.aab1140

Conn, C. E., and Nelson, D. C. (2016). Evidence that KARRIKININSENSITIVE2 (KAI2) receptors may perceive an unknown signal that is not karrikin or strigolactone. Front. Plant Sci. 6:1219. doi: 10.3389/fpls.2015. 01219

de Saint Germain, A., Clavé, G., Badet-Denisot, M.-A., Pillot, J.-P., Cornu, D., Le Caer, J.-P., et al. (2016). An histidine covalent receptor and butenolide complex mediates strigolactone perception. Nat. Chem. Biol. 12, 787-794. doi: $10.1038 /$ nchembio. 2147

Delaux, P.-M., Xie, X., Timme, R. E., Puech-Pages, V., Dunand, C., Lecompte, E., et al. (2012). Origin of strigolactones in the green lineage. New Phytol. 195, 857-871. doi: 10.1111/j.1469-8137.2012.04209.x

Dyer, B. W., Ferrer, F. A., Klinedinst, D. K., and Rodriguez, R. (2000). A noncommercial dual luciferase enzyme assay system for reporter gene analysis. Anal. Biochem. 282, 158-161. doi: 10.1006/abio.2000.4605

Flematti, G. R., Ghisalberti, E. L., Dixon, K. W., and Trengove, R. D. (2004). A compound from smoke that promotes seed germination. Science 305, 977-977. doi: 10.1126/science.1099944

Flematti, G. R., Goddard-Borger, E. D., Merritt, D. J., Ghisalberti, E. L., Dixon, K. W., and Trengove, R. D. (2007). Preparation of 2H-Furo[2,3-c]pyran-2-one derivatives and evaluation of their germination-promoting activity. J. Agric. Food Chem. 55, 2189-2194. doi: 10.1021/jf0633241

Flematti, G. R., Waters, M. T., Scaffidi, A., Merritt, D. J., Ghisalberti, E. L., Dixon, K. W., et al. (2013). Karrikin and cyanohydrin smoke signals provide clues to new endogenous plant signaling compounds. Mol. Plant 6, 29-37. doi: 10.1093/ $\mathrm{mp} / \mathrm{sss} 132$

Goddard-Borger, E. D., Ghisalberti, E. L., and Stick, R. V. (2007). Synthesis of the germination stimulant 3-methyl-2H-furo[2,3-c]pyran-2-one and analogous compounds from carbohydrates. Eur. J. Org. Chem. 38, 3925-3934. doi: 10. 1002/ejoc.200700334

Guo, Y., Zheng, Z., La Clair, J. J., Chory, J., and Noel, J. P. (2013). Smokederived karrikin perception by the $\alpha / \beta$-hydrolase KAI2 from Arabidopsis. Proc. Natl. Acad. Sci. U.S.A. 110, 8284-8289. doi: 10.1073/pnas.13062 65110

Hamiaux, C., Janssen, B. J., Ledger, S. E., Cooney, J. M., Newcomb, R. D., and Snowden, K. C. (2012). DAD2 is an $\alpha / \beta$ hydrolase likely to be Involved in the perception of the plant branching hormone, strigolactone. Curr. Biol. 22, 2032-2036. doi: 10.1016/j.cub.2012.08.007

Jiang, L., Liu, X., Xiong, G., Liu, H., Chen, F., Wang, L., et al. (2013). DWARF 53 acts as a repressor of strigolactone signalling in rice. Nature 504, 401-405. doi: $10.1038 /$ nature 12870

Kagiyama, M., Hirano, Y., Mori, T., Kim, S.-Y., Kyozuka, J., Seto, Y., et al. (2013). Structures of D14 and D14L in the strigolactone and karrikin signaling pathways. Genes Cells 18, 147-160. doi: 10.1111/gtc.12025

Karimi, M., Inzé, D., and Depicker, A. (2002). GATEWAYTM vectors for Agrobacterium-mediated plant transformation. Trends Plant Sci. 7, 193-195. doi: 10.1016/S1360-1385(02)02251-3

Liu, W. C., and Carnsdagger, H. R. (1961). Isolation of abscisin, an abscission accelerating substance. Science 134, 384-385. doi: 10.1126/science.134. 3476.384

Mander, L. N. (2003). Twenty years of gibberellin research. Nat. Prod. Rep. 20, 49-69. doi: 10.1039/b007744p

Nelson, D. C., Riseborough, J. A., Flematti, G. R., Stevens, J., Ghisalberti, E. L., Dixon, K. W., et al. (2009). Karrikins discovered in smoke trigger Arabidopsis seed germination by a mechanism requiring gibberellic acid synthesis and light. Plant Physiol. 149, 863-873. doi: 10.1104/pp.108.131516
Nelson, D. C., Scaffidi, A., Dun, E. A., Waters, M. T., Flematti, G. R., Dixon, K. W., et al. (2011). F-box protein MAX2 has dual roles in karrikin and strigolactone signaling in Arabidopsis thaliana. Proc. Natl. Acad. Sci. U.S.A. 108, 8897-8902. doi: 10.1073/pnas.1100987108

Osborne, D. J. (1955). Acceleration of abscission by a factor produced in senescent leaves. Nature 176, 1161-1163. doi: 10.1038/1761161a0

Scaffidi, A., Waters, M. T., Ghisalberti, E. L., Dixon, K. W., Flematti, G. R., and Smith, S. M. (2013). Carlactone-independent seedling morphogenesis in Arabidopsis. Plant J. 76, 1-9. doi: 10.1111/tpj.12265

Scaffidi, A., Waters, M. T., Sun, Y. K., Skelton, B. W., Dixon, K. W., Ghisalberti, E. L., et al. (2014). Strigolactone hormones and their stereoisomers signal through two related receptor proteins to induce different physiological responses in Arabidopsis. Plant Physiol. 165, 1221-1232. doi: 10.1104/pp.114. 240036

Soundappan, I., Bennett, T., Morffy, N., Liang, Y., Stanga, J. P., Abbas, A., et al. (2015). SMAX1-LIKE/D53 family members enable distinct MAX2dependent responses to strigolactones and karrikins in Arabidopsis. Plant Cell 27, 3143-3159. doi: 10.1105/tpc.15.00562

Stanga, J. P., Morffy, N., and Nelson, D. C. (2016). Functional redundancy in the control of seedling growth by the karrikin signaling pathway. Planta 243, 1397-1406. doi: 10.1007/s00425-015-2458-2

Stanga, J. P., Smith, S. M., Briggs, W. R., and Nelson, D. C. (2013). SUPPRESSOR OF MORE AXILLARY GROWTH2 1 controls seed germination and seedling development in Arabidopsis. Plant Physiol. 163, 318-330. doi: 10.1104/pp.113. 221259

Toh, S., Holbrook-Smith, D., Stogios, P. J., Onopriyenko, O., Lumba, S., Tsuchiya, Y., et al. (2015). Structure-function analysis identifies highly sensitive strigolactone receptors in Striga. Science 350, 203-207. doi: 10.1126/science. aac9476

Waldie, T., McCulloch, H., and Leyser, O. (2014). Strigolactones and the control of plant development: lessons from shoot branching. Plant J. 79, 607-622. doi: $10.1111 /$ tpj.12488

Wang, L., Wang, B., Jiang, L., Liu, X., Li, X., Lu, Z., et al. (2015). Strigolactone signaling in Arabidopsis regulates shoot development by targeting D53-Like SMXL repressor proteins for ubiquitination and degradation. Plant Cell 27, 3128-3142. doi: 10.1105/tpc. 15.00605

Waters, M. T., Nelson, D. C., Scaffidi, A., Flematti, G. R., Sun, Y. K., Dixon, K. W., et al. (2012). Specialisation within the DWARF14 protein family confers distinct responses to karrikins and strigolactones in Arabidopsis. Development 139, 1285-1295. doi: 10.1242/dev.074567

Waters, M. T., Scaffidi, A., Flematti, G., and Smith, S. M. (2015a). Substrateinduced degradation of the $\alpha / \beta$-fold hydrolase KARRIKIN INSENSITIVE2 requires a functional catalytic triad but is independent of MAX2. Mol. Plant 8, 814-817. doi: 10.1016/j.molp.2014.12.020

Waters, M. T., Scaffidi, A., Sun, Y. K., Flematti, G. R., and Smith, S. M. (2015b). A Selaginella moellendorffii ortholog of KARRIKIN INSENSITIVE2 functions in Arabidopsis development but cannot mediate responses to karrikins or strigolactones. Plant Cell 27, 1925-1944. doi: 10.1105/tpc.15. 00146

Xu, Y., Miyakawa, T., Nakamura, H., Nakamura, A., Imamura, Y., Asami, T., et al. (2016). Structural basis of unique ligand specificity of KAI2-like protein from parasitic weed Striga hermonthica. Sci. Rep. 6:31386. doi: 10.1038/srep 31386

Yamaguchi, I., Yokota, T., Murofushi, N., Ogawa, Y., and Takahashi, N. (1970). Isolation and structure of a new gibberellin from immature seeds of Prunus persica. Agric. Biol. Chem. 34, 1439-1441. doi: 10.1080/00021369.1970. 10859793

Yao, R., Ming, Z., Yan, L., Li, S., Wang, F., Ma, S., et al. (2016). DWARF14 is a non-canonical hormone receptor for strigolactone. Nature 536, 469-473. doi: $10.1038 / 533469$ a

Yasuda, N., Sugimoto, Y., Kato, M., Inanaga, S., and Yoneyama, K. (2003). (+)-Strigol, a witchweed seed germination stimulant, from Menispermum dauricum root culture. Phytochemistry 62, 1115-1119. doi: 10.1016/S00319422(02)00679-9

Zhao, L.-H., Zhou, X. E., Wu, Z.-S., Yi, W., Xu, Y., Li, S., et al. (2013). Crystal structures of two phytohormone signal-transducing $\alpha / \beta$ hydrolases: karrikinsignaling KAI2 and strigolactone-signaling DWARF14. Cell Res. 23, 436-439. doi: $10.1038 / \mathrm{cr} .2013 .19$ 
Zhou, F., Lin, Q., Zhu, L., Ren, Y., Zhou, K., Shabek, N., et al. (2013). D14-SCFD3dependent degradation of D53 regulates strigolactone signalling. Nature 504, 406-410. doi: $10.1038 /$ nature 12878

Conflict of Interest Statement: The authors declare that the research was conducted in the absence of any commercial or financial relationships that could be construed as a potential conflict of interest.
Copyright $\odot 2016$ Sun, Flematti, Smith and Waters. This is an open-access article distributed under the terms of the Creative Commons Attribution License (CC BY). The use, distribution or reproduction in other forums is permitted, provided the original author(s) or licensor are credited and that the original publication in this journal is cited, in accordance with accepted academic practice. No use, distribution or reproduction is permitted which does not comply with these terms. 